\title{
FICÇÕES NARCISISTAS E CONFIGURAÇÕES NÔMADES NA NARRATIVA MODERNA
}

NARCISSISTIC FICTION AND NOMADIC FEATURES IN MODERN NARRATIVE

\author{
Mariângela Alonso \\ Universidade Estadual Paulista "Júlio de Mesquita Filho"
}

\begin{abstract}
RESUMO: Este artigo visa à discussão do arcabouço ficcional de dois escritores do século XX, André Gide (1869-1951) e Clarice Lispector (1920-1977). A partir dos conceitos de Linda Hutcheon (1980) e Lucien Dallenbach (1977) acerca da ficção narcisista e de Alain Goulet (2006) a respeito do procedimento do autor en abyme, tecemos algumas considerações sobre os processos de autoconsciência textual e autorreferencialidade contidos na metaficção. Assim, chamaremos a atenção para o fenômeno da mise en abyme, recurso frequentemente utilizado na metaficção como modus operandi das narrativas narcisistas de Gide e Lispector.
\end{abstract}

PALAVRAS-CHAVE: mise en abyme; André Gide; Clarice Lispector.

ABSTRACT: This paper aims to discuss the fictional framework of two writers of the 20th century, André Gide (1869-1951) and Clarice Lispector (1920-1977). Based on the concepts of Linda Hutcheon (1980) and Lucien Dallenbach (1977) about the narcissistic fiction and Alain Goulet (2006) about the author en abyme procedure, we weave some considerations about the textual self processes and self-referentiality contained in metafiction. Thus, we call attention to the phenomenon of mise en abyme, feature often used in metafiction as modus operandi of Gide and Lispector's narcissistics narratives.

KEYWORDS: mise en abyme; André Gide; Clarice Lispector.

\section{Introdução}

Enquanto espelho de si, a literatura, por vezes, engolfa-se em sua interioridade, desdobrando-se em imagens vertiginosas. Muito mais do que uma forma ou estrutura, o procedimento da mise en abyme propicia o trabalho expressivo da palavra, caracterizando-se pela criatividade e tomada de consciência de seus autores, sobretudo por meio do viés crítico oferecido pela metalinguagem. Nesta perspectiva, este artigo procurará demonstrar a potencialidade da metáfora especular na literatura de Clarice Lispector e André Gide.

O procedimento narrativo da mise en abyme constitui-se na desarticulação da massa textual, intervindo na rede de relações, de modo a assinalar a intersecção de encadeamentos significativos diversos, isto é, um interessante jogo narrativo especular. Trata-se de uma das formas mais empregadas pela literatura no intento de refletir sobre si 


\section{Revista do SELL}

v. 5 , no. 2

ISSN: $1983-3873$

mesma, ou seja, um processo de autorreflexão, denominado mise en abyme pelo escritor André Gide em 1893.

A imagem en abyme que seduz Gide é oriunda da heráldica e representa um escudo contendo em seu centro uma miniatura de si mesma, de modo a indicar um processo de profundidade e infinito, o que parece sugerir, no campo literário, noções de reflexo, espelhamento:

J'aime assez qu'en une œuvre d'art on retrouve ainsi transposé, à l'échelle des personnages, le sujet même de cette œuvre. Rien ne l'éclaire mieux et n'établit plus sûrement toutes les proportions de l'ensemble. Ainsi, dans tels tableaux de Memling ou de Quentin Metzys, un petit miroir convexe et sombre reflète, à son tour, l'intérieur de la pièce où se joue la scène peinte. Ainsi, dans le tableau des Ménines de Velasquez (mais un peu différemment). Enfin, en littérature, dans Hamlet, la scène de la comédie; et ailleurs dans bien d'autres pièces. Dans Wilhelm Meister, les scènes de marionnettes ou de fête au château. Dans La chute de la maison Usher, la lecture que l'on fait à Roderick, etc. Aucun de ces exemples n'est absolument juste. Ce qui le serait beaucoup plus, ce qui dirait mieux ce que j'ai voulu dans mes Cahiers, dans mon Narcisse et dans La tentative, c'est la comparaison avec ce procédé du blason qui consiste, dans le premier, à en mettre un second 'en abyme'. (GIDE, 1948, p. 41 apud DALLENBACH, 1977, p. 15)

De acordo com os heraldistas, o escudo é o elemento central do brasão; é nele que estão contidos os caracteres distintivos ${ }^{1}$. O termo abyme, por sua vez, alude ao centro do escudo, quando as peças aí inseridas portam dimensões menores, revelando um espaço de miniaturização de figuras, configuração que levou Gide a perfilhar por analogia o procedimento do encaixe narrativo.

A fim de explanar e tornar mais clara a especularidade da figura heráldica tomada por Gide, Lucien Dallenbach (1977) atenta para as comparações à exaustão com as bonecas russas e as caixas chinesas, as quais se engendram umas às outras, bem como as pirâmides mexicanas, que se encaixam e se refletem mutuamente; os cartazes publicitários, reproduzindo seus motivos ao infinito e em perspectiva e ainda a famosa fita de Moebius, cujas faces interna e externa permutam-se, invertendo sua identidade.

A autorreflexão presente no procedimento da mise en abyme parece coincidir com os estudos de Roland Barthes (2007) em importante ensaio acerca das distinções entre

\footnotetext{
${ }^{1}$ Cf. ZUQUETE, Afonso Eduardo Martins. Armorial lusitano: genealogia e heráldica. Lisboa: Editorial Enciclopédia, 1961.
} 


\section{Revista do SELL}

v. 5 , no. 2

ISSN: $1983-3873$

linguagem-objeto e metalinguagem. Para Barthes, a metalinguagem é um componente expressivo, localizado no âmago do próprio objeto literário:

Durante séculos nossos escritores não imaginavam que fosse possível considerar a literatura (a própria palavra é recente) como uma linguagem, submetida, como qualquer outra linguagem, à distinção lógica: a literatura nunca refletia sobre si mesma (às vezes sobre suas figuras, mas nunca sobre seu ser), nunca se dividia em objeto ao mesmo tempo olhante e olhado; em suma, ela falava mas não se falava. Mais tarde, provavelmente com os primeiros abalos da boa consciência burguesa, a literatura começou a sentir-se dupla: ao mesmo tempo objeto e olhar sobre esse objeto, fala e fala dessa fala, literatura-objeto e metaliteratura. (BARTHES, 2007, p. 27)

Desse modo, o processo de escrita decorrente da mise en abyme instaura a investigação sobre o próprio ato criador que envolve a literatura. Espécie de construto artístico e crítico, a obra literária torna-se um objeto "olhante e olhado", que questiona e é também questionado.

Como marca do "código metalinguístico", o exercício especular da mise en abyme apresenta essencialmente o acúmulo de "propriedades vulgares da iteração e do enunciado de segundo grau" (DALLENBACH, 1979, p. 54), os quais caracterizam-se por uma estrutura rica e intensa em questionamento, capaz de fazer a obra literária "[...] dialogar consigo mesma e de a prover dum aparelho de autointepretação" (DALLENBACH, 1979, p. 54).

Quanto às reflexões empreendidas por Gide, merecem destaque os argumentos em torno da tela As meninas, de Diego Velásquez (1599-1660). Esta pintura tem como projeto a captação de uma cena palaciana da corte imperial de Filipe IV. Na parte central do quadro, encontram-se a infanta Margarida e suas damas de companhia. Curiosamente, desponta, no canto esquerdo da tela, o autorretrato do pintor espanhol, que se coloca, portanto, como objeto e sujeito de sua própria obra².

\footnotetext{
${ }^{2}$ Cf. BROWN, Jonathan. Imágenes e ideas en la pintura española del siglo XVII. Madrid: Alianza Editorial,
} 1980. p. 115-142. 


\section{Revista do SELL}

v. 5 , no. 2

ISSN: $1983-3873$

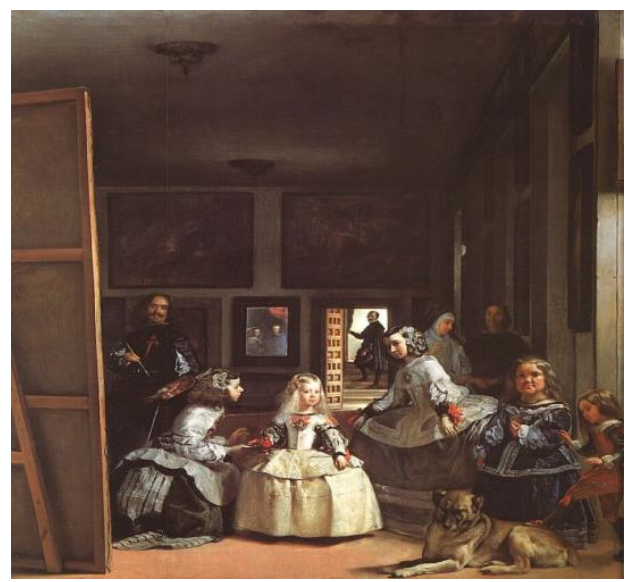

FIGURA 1. VELÁSQUEZ, Diego. As meninas (1656). Óleo sobre tela. 3,10 x 2,76, Museu do Prado, Madrid.

Na visão de Michel Foucault (1926-1984), a obra de Velásquez engendra um questionamento acerca da noção clássica de representação, na medida em que estabelece um espaço que parece exterior ao cenário e paradoxalmente lhe pertence, já que poderia configurar-se como o lugar do próprio espectador: "O pintor olha, o rosto ligeiramente virado e a cabeça inclinada para o ombro. Fixa um ponto invisível, mas que nós, espectadores, podemos facilmente determinar, pois que esse ponto somos nós: 0 nosso corpo, o nosso rosto, os nossos olhos" (FOUCAULT, 1999, p. 4). Mais ao fundo, há a figura de um homem que toca uma cortina, conferindo à obra de Velásquez ainda mais movimento e luminosidade. No segundo plano, mais especificamente sobre a parede do fundo da sala, surge a figura de um espelho em que estão refletidos o rei e a sua segunda esposa e sobrinha, Mariana de Áustria.

A intervenção do espelho torna a cena ambígua, já que o espectador não tem certeza de quem seria ali retratado. Assim, o espelho reflete o que não é acessível à tela e ao mesmo tempo revela certa incongruência em relação ao todo representado. $\mathrm{Na}$ esteira dos estudos foucaultianos, Dallenbach atesta:

[...] le miroir réalise une réciprocité des regards qui fait osciller l'interieur et l'extérieur, marie reflets reflétants et reflets réfléchis et pousse l'image à sortir de son cadre em même temps qu'il convie les visiteurs à entrer dans le tableau.(DALLENBACH, 1972, p. 64).

Desse modo, a capacidade reveladora de permitir o alcance de elementos não acessíveis à visão pura torna possível a discussão em torno da intrigante estrutura abismal presente nos espelhos. Nesse contexto, a mise en abyme surge como procedimento narrativo associado à função especular, caracterizando-se como um 


\section{Revista do SELL}

v. 5 , no. 2

ISSN: $1983-3873$

instrumento de realce à imagem refletida em sua duplicidade. Seu funcionamento reitera os contornos e propriedades do objeto refletido.

A mise en abyme também ganhou destaque nos anos 60, sobretudo com 0 nouveau roman ${ }^{3}$, tal como atestam os estudos de Jean Ricardou em Le nouveau roman (1978). Para Ricardou, a mise en abyme constitui-se em um procedimento retórico de duplicação interior, capaz de gerar interessantes jogos reflexivos nas narrativas. Assim, o estudioso dedica-se à análise de diferentes textos do nouveau roman, antepondo, em relação à construção em abismo, duas qualidades narrativas básicas, ser reveladora e ser antitética.

A capacidade da mise en abyme de resumir, em variantes, desvelando, por meio de desdobramento metonímico, aspectos maiores da ficção, constituiria o que Ricardou chamou de revelação. Nesse caso, a unidade narrativa é contestada, operando por identidade ou diferença; estariam aí subentendidas as funções de repetição, condensação e antecipação. O estudioso exemplifica a partir das obras de Alain Robbe-Grillet (19222008) e Michel Butor (1926- ), sinalizando:

avec Le Voyeur, Alain Robbe-Grillet propose une scène en abyme (um miroir faisant paraître, d'une chambre, sa partie soustraite au regard de l'observateur) trahissant le viol que Mathias, précisément, s'efforce de dissimuler; dans l'Emploi du temps, Michel Butor dispose, avec le vitrail de Cain, qui joint une pluie de sang à un immense incendie, une marque accusatrice, ou comme le déclare évasivement le narrateur: 'ce signe majeur qui a organisé toute ma vie dans notre année, Bleston'. (RICARDOU, 1978, p. 51).

Ricardou aposta na hipótese de substituição da visão crítica da mise en abyme como micro história de uma macro história, insistindo na ideia de uma macro história como mise en périphérie de uma micro narrativa. Assim, os acontecimentos contidos na mise en abyme não seriam apenas presságios, oráculos ou profecias miméticas, mas "il s'apparenterait moins à une opération augurale qu'à une activité magique; il serait moins une expression anticipée que la base d'une production" (RICARDOU, 1978, p. 54).

\footnotetext{
${ }^{3}$ Termo utilizado para designar um conjunto de romances franceses publicados no período do pós-guerra. A expressão foi cunhada pelo escritor francês Allain Robbe-Grillet (1922-2008) e discutida por ele no ensaio intitulado Por um novo romance: "[...] trata-se apenas de um rótulo cômodo que engloba todos aqueles que procuram novas formas de romance, capazes de exprimir (ou de criar) novas relações entre o homem e o mundo, todos aqueles que se decidiram a inventar o romance, isto é, a inventar o homem". (Cf. ROBBEGRILLET, Alain. Por um novo romance. Tradução T. C. Netto. São Paulo: Documentos, 1969. p. 8).
} 


\section{Revista do SELL}

v. 5 , no. 2

ISSN: $1983-3873$

Por sua vez, a antítese contaria com o fato de a construção em abismo contradizer o funcionamento global do texto, quebrando-Ihe a unidade narrativa, surgindo, assim, sequências fragmentadas de narrativas articuladas. Procedendo por similitude e redução, a mise en abyme antitética multiplica as semelhanças, as quais, por meio das repetições, são capazes de aproximar e rearticular os diversos acontecimentos. Ricardou utiliza como ilustração o romance Les corps conducteurs (1971), de Claude Simon (1913-2005): "dans Les corps conducteurs, l'idée de trajectoire s'accrédite-t-elle surtout avec la séquence typique de la forêt, puis souligne-t-elle, em sa répétition, les divers autres trajets plus violemment morcelés" (RICARDOU, 1978, p. 75).

Nesse sentido, a mise en abyme acaba por fragmentar a unidade metonímica da obra, segundo uma estratificação de narrativas metafóricas, dotando-a de uma estrutura forte, e, assim, assegurando-lhe um significado superior. Conforme atesta Ricardou: "Tel est son rôle antithétique: l'unité, elle la divise, la dispersion, elle l'unit' (RICARDOU, 1978, p. 75).

A mise en abyme corresponde, pois, a um meio capaz de transformar e transgredir a narrativa, apresentando-se como parte integrante de um objeto estético. Sem perder de vista tais pressupostos, procuraremos mostrar, nas páginas seguintes, como as narrativas de André Gide e Clarice Lispector revisitam algumas destas questões, revelando o diálogo e a continuidade crítica do conceito.

\section{Espelho, espelho meu...}

"A minha imagem, tal qual eu a via nos espelhos, anda sempre ao colo da minha alma" Bernardo Soares

No estudo Narcissistic narrative: the metafictional paradox (1980), Linda Hutcheon (1947- ) dedica algumas páginas à narrativa narcisista, alargando, assim, os horizontes críticos para além do domínio francês, com exemplos de escritores como Borges (18991986), Nabokov (1899-1977) e Barth (1930- ).

A partir do adjetivo narcissistic, que designa a autoconsciência textual, a discussão de Hutcheon abrange os diversos tipos de autorreferencialidade contidos na metaficção. Assim, a estudiosa chama a atenção para a mise en abyme e a alegoria, recursos frequentemente utilizados na metaficção como modus operandi da narrativa narcisista. 


\section{Revista do SELL}

v. 5 , no. 2

ISSN: $1983-3873$

Tais recursos tendem a expor o status ficcional da obra literária, partilhando com o leitor a própria poiesis e construção do texto por meio do processo de leitura.

Para fins de exemplificação, Hutcheon recorre ao final do conto Averroes' search (La busca de Averroes) (1947), de Jorge Luis Borges, em que o narrador tematiza a mise en abyme ao dizer ao leitor:

I sensed, on the last page, that my narrative was a symbol of the man I was while I wrote it, and that to write that story I had to be that man, and that to be that man I had to write that story and so to infinity. (The instant I stop believing in him 'Averroes' disappears). (BORGES, 1967, p. 110 apud HUTCHEON, 1980, p. 54)

Além do conto borgiano, a autora evoca o romance The real life of Sebastian Knight (1941), de Vladimir Nabokov (1899-1977), em que cada uma das narrativas funciona como uma mise en abyme do próprio romance de Nabokov. É o que acontece, por exemplo, na primeira parte, com a narrativa policial intitulada "The prismatic bezel", em que o narrador, denominado $\mathrm{V}$, procura desvendar, por meio de pistas, a verdadeira história de seu irmão Sebastian Knight, um famoso escritor já falecido. Vale ressaltar que este fato soa como uma pista para o status do herói do próprio texto que o leitor está lendo: "At any rate, Nabokov's novel is also about a detective ( $\mathrm{V}$, Knight's brother) who hunts for clues to a man's life and death" (HUTCHEON, 1980, p. 54).

Com isso, Hutcheon constata que a mise en abyme pode ser abrangente e complexa, possibilitando sua descrição como um tipo de alegoria. É o que pode ser observado com o narrador de Lost in the funhouse (1968), de John Barth, que narra a história de Ambrose, um garoto de treze anos. Acresce que o narrador, ele mesmo Ambrose, afirma-se como autor ficcional ao comentar os problemas e as dificuldades de composição da obra que está narrando (também intitulada Lost in the funhouse) sobre o personagem denominado Ambrose, que está perdido em uma funhouse ${ }^{4}$, num processo extremamente complexo de ambiguidade e espelhamento: "The narrator becomes confused, forgets the direction of his narration, becomes lost in 'Lost in the funhouse' which is itself lost in the middle of the collection, Lost in the funhouse" (HUTCHEON, 1980, p. 56).

\footnotetext{
${ }^{4}$ A palavra funhouse significa um espaço situado em parques de diversão, geralmente equipado com truques de espelhos, pisos e tetos inconstantes, além de outros efeitos produzidos para assustar ou divertir as pessoas que caminham ao seu redor. Por não haver um correspondente direto em português, manteremos o termo em inglês.
} 


\section{Revista do SELL}

v. 5 , no. 2

ISSN: $1983-3873$

Todo este jogo confuso e espelhado tende a funcionar como uma alegoria da posição do leitor que, tal como Ambrose, encontra-se perdido, procurando um caminho possível em meio aos labirintos vertiginosos do enredo.

O texto é, portanto, permeado por uma dinâmica bastante nômade entre o eu que escreve, o eu que narra e ainda o eu narrado. Sem se fundirem ou se excluírem totalmente, tais instâncias revelam-se vertiginosas frente ao leitor, evidenciando uma espécie de porosidade nas fronteiras do jogo ficcional. Enquanto autor ficcional da trama que narra, Ambrose está a serviço da empreitada metaficcional do autor John Barth, o qual parece confrontar e desautorizar criticamente a sua identidade de escritor ao exercício ficcional do narrador criado.

A narrativa se sujeita ao trânsito, ao nomadismo de instâncias, propondo novas configurações estéticas à obra literária. Tal dinâmica afeta diretamente o leitor, sobretudo no que tange à capacidade interpretativa e criativa deste na atribuição de sentidos.

Essa dinâmica também é eficientemente desenvolvida por Clarice Lispector em $A$ hora da estrela, a partir do jogo de identidade que a autora estabelece consigo mesma e com suas personagens. Conforme mencionamos anteriormente, Rodrigo S.M, faz-se personagem da trama, espelha-se em Macabéa, e acaba por favorecer o jogo de especularidades e identidades. Assim como Macabéa, Rodrigo também é nordestino e sofre de certa marginalidade social, apresentada ao leitor com viés irônico em torno de sua literatura: "Sim, não tenho classe social, marginalizado que sou. A classe alta me tem como um monstro esquisito, a média com desconfiança de que eu possa desiquilibrá-la, a classe baixa nunca vem a mim". (LISPECTOR, 1993, p. 33).

Além do narrador Rodrigo, a presença da própria escritora emerge em $A$ hora da estrela, explicitamente anunciada na "Dedicatória do autor (Na verdade Clarice Lispector)" (LISPECTOR, 1993, p. 21). De modo ainda mais provocador, tal presença é reforçada pelo nome da autora, que surge em meio aos treze títulos da narrativa, em claro sinal de comprometimento com o ato de sua escrita e o jogo de identidade. Segundo Benedito Nunes, "Clarice Lispector faz-se igualmente personagem", destituindo-se da "máscara pública de ficcionista” (1998, p. 40).

Ainda que tenha criado um narrador interposto, nossa escritora não se omite da empreitada narrativa, uma vez que apresenta, através de Rodrigo S.M, preocupações de ordem literária, como em: "[...] também eu não faço a menor falta, e até o que escrevo um outro escreveria. Um outro escritor, sim, mas teria que ser homem porque escritora 


\section{Revista do SELL}

v. 5 , no. 2

ISSN: $1983-3873$

mulher pode lacrimejar piegas" (LISPECTOR, 1993, p. 28). Por meio das entrelinhas, a passagem parece inferir a autora e corroborar um certo posicionamento acerca dos discursos da mulher escritora. O tom é irônico e de zombaria, uma vez que Lispector valese de um narrador, encarnado em um escritor-personagem para narrar a história de Macabéa, moça "incompetente para a vida" (LISPECTOR, 1993, p. 39), escarnecendo, desse modo, de todo o legado da narrativa brasileira anterior a sua obra.

O jogo de espelhamentos entre escritora, narrador e personagens presente em $A$ hora da estrela denota a constante procura da autora por si mesma, ao mesmo tempo em que ganham forma discussões acerca da problematização do literário. É o que percebemos na entrevista que concedeu ao jornalista Júlio Lerner, em fevereiro de 1977. Quando questionada a respeito da nova personagem, Clarice ressalta a origem nordestina como um possível gérmen da criação de Macabéa: "Eu morei em Recife... eu morei no nordeste... eu me criei no nordeste... e... depois, ahn, no Rio de Janeiro tem uma feira dos nordestinos... no Campo de São Cristóvão e uma vez eu fui lá"5.

De acordo com Edgar Nolasco, o jogo de identidade como uma espécie de constructo ficcional é algo que sempre esteve presente na obra clariciana:

No início de seu projeto literário, o ficcional seria o lugar onde o traço biográfico se escondia; no decorrer desse projeto acontece justamente o oposto: agora é o ficcional que vai ficar 'colado' ao vivido, confundindo-se com ele. Tudo isto porque a autora não só fez de sua vida matéria para a ficção, como tornou-se, de forma singularíssima, seu próprio tema ficcional. (NOLASCO, 2004, p. 78-79)

Além de $A$ hora da estrela, outras produções dão conta destes fatores, tais como os contos "Restos do carnaval" e "Cem anos de perdão", que trazem a memória e a infância ficcionalizadas como elementos imprescindíveis à construção literária: "[...] reapropriações que a escritora faz de si mesma enquanto ser ficcionalizado" (NOLASCO, 2004, p. 79). Dessa forma, rastrear o texto clariciano e seus espelhamentos, significa, antes de mais nada, percorrer a tentativa de compreensão de um projeto ficcional, aberto, nômade e espelhado.

De certo modo análoga está a categoria do chamado l'auteur en abyme, postulada pelo crítico Allain Goulet (2006). Para dar início à discussão em torno deste procedimento, o estudioso toma como exemplo a obra Monsieur Teste (1925), de Paul Valéry,

\footnotetext{
${ }^{5}$ Cf. "Panorama especial com Clarice Lispector". TV Cultura. São Paulo. Entrevista a Júlio Lerner. Gravada em 01 de fevereiro de 1977 e exibida no dia 28 de dezembro de 1977, às 20: 30h.
} 


\section{Revista do SELL}

v. 5 , no. 2

ISSN: $1983-3873$

mostrando como o protagonista, espécie de alter ego do autor, ao lado de conflitos internos, dá margem ao jogo vertiginoso da mise en abyme. A passagem abaixo permite adentrar o pensamento de $\mathrm{M}$. Teste e, por meio dele, o método de pensamento a que pretendia Valéry:

[M. Teste] avait sur tout le monde un avantage qu'il s'était donné: celui de posséder une idée commode de lui-même; et, dans chacune de ses pensées entrait un autre Monsieur Teste, un personnage bien connu, simplifié, uni au véritable par tous ses points... II avait en somme substitué au vague soupçon du Moi qui altère tous nos propres calculs [...] un être imaginaire defini, un Soi-Même bien déterminé, ou éduqué, sur comme un instrument, sensible comme un animal. (VALÉRY, 1960, p. 59 apud GOULET, 2006, p. 45).

Para Goulet, o alter ego não constitui uma cópia idêntica ou o modelo reduzido de seu autor, mas antes, a projeção de um ponto de vista peculiar, do despojamento da escrita, explorando a ficção fora da obra literária. Trata-se da transposição ou figuração em modelo reduzido do sujeito da obra exposto ao interior da ficção: "L'auteur en abyme focalise certaines questions et certains traits, d'une façon nécessairement stylisée, grossie, mise à distance" (GOULET, 2006, p. 45).

Nesse sentido, l'auteur en abyme fornece uma crítica de seus personagens e métodos de construção, na medida em que permite o exame das estruturas fundamentais da ficção narrativa pautadas no jogo complexo entre o eu e o outro.

A mise en abyme implica no desnudamento do processo de criação artística da obra literária, no que tange a autoanálise e a autorreflexão de seu autor. Tal processo possibilita, muitas vezes, o efeito performativo do mecanismo de projeção do eu do autor no outro da ficção. Esse procedimento é o ponto de partida da reflexão empreendida por Gide quando da teorização do conceito, cerne mesmo de toda sua obra: "L'auteur en abyme est donc un instrument de prise de conscience des processus et des circonstances à l'oeuvre dans l'écriture, au cours de la rédaction, et donc une tentative de les contrôler de l'intérieur"' (GOULET, 2006, p. 45).

O crítico atenta para o princípio de retroação de Les faux-monnayeurs, destacando o narrador Edouard e a confecção de seu diário. Para Goulet, Edouard assume-se como agente da obra gidiana, encarnando a figura do autor en abyme, uma vez que apresenta posicionamentos frente à construção do romance que está fazendo, apesar de estar envolvido e controlado por um narrador que interfere enquanto regente e juiz da trama: 


\section{Revista do SELL}

v. 5 , no. 2

ISSN: $1983-3873$

"Incarnation vivante de la tension entre l'ordre de la vie et de la littérature, il ne peut être que faux-monnayeur du réel" (GOULET, 2006, p. 55).

Dessa forma, Edouard propicia ao romance de Gide a crítica do autor onisciente, revelando algo como um exercício de interrogação da obra ao abarcar, por vezes, uma espécie de escárnio ou autoflagelação, à medida que permeia pela escrita os limites de seu próprio poder demiúrgico: "Si je ne parviens pas à l'écrire, ce livre, c'est que l'histoire du livre m'aura plus intéressé que le livre lui-même; qu'elle aura pris sa place; et ce será tant mieux" (GIDE, 1948, p. 1083 apud GOULET, 2006, p. 46).

Essencialmente metalinguística, a narrativa de Les faux-monnayeurs ofereceu ao autor francês o ensejo de discutir os procedimentos fundamentais da condução da obra, questionando os limites de sua criação e caracterização:

Despojar o romance de todos os elementos que não pertençam especificamente ao romance. [...] Mesmo a descrição dos personagens não me parece pertencer convenientemente ao gênero. Sim, realmente, não me parece que o romance puro (e em arte, como em tudo, só a pureza me interessa) deva se ocupar dela. [...] O romancista, em geral, não dá suficiente crédito à imaginação do leitor. (GIDE, 1983, p. 66)

O exercício interpretativo de Gide em torno da mise en abyme é bastante pertinente e nos faz atentar para a relação crítica de especularidade presente no jogo entre o mesmo e o outro. A imagem de um objeto refletida pelo espelho pressupõe 0 objeto ainda que não seja o objeto, propriamente. Na obra gidiana, a narrativa primeira funciona como o enunciado refletido, espelhado na segunda narrativa, que, por sua vez, reflete criticamente sobre a primeira. Conforme evidencia Dallenbach:

Le dédoublement, ici, s'opère sous nos yeux: représentation seconde, II devient copie de la copie, image de l'image, de sorte que l'oeuvre peut par ce retour sur elle-même, satisfaire ses tendances narcissiques et se mirer dans le miroir de son propre spectacle. (DALLENBACH, 1972, p. 66)

Les cahiers d'André Walter (1891) é a obra inaugural de Andre Gide, a qual reúne os seus desassossegos literários e subjetivos, propondo um interessante tratado especular. Nessa obra, Walter é um escritor e seu livro chama-se Allain. Walter enlouquece, morrendo antes de concluir o livro, cujo tema constitui-se dos devaneios e sofrimentos amorosos do personagem Allain.

A especularidade aí empreendida por Gide permite o retorno da obra sobre si mesma, propiciando seu questionamento: "Les cahiers d'André Walter mettent en scène, de façon exemplaire, la genèse d'un auteur, les conditions et les circonstances de son 


\section{Revista do SELL}

v. 5 , no. 2

ISSN: $1983-3873$

écriture, et la dialectique qui s'instaure entre l'auteur et son double" (GOULET, 2006, p. 48).

Ademais, as ações experienciadas através de outro ser ficcional resguardam o escritor, poupando-o do comprometimento direto com a vida real, além de consentir certo distanciamento crítico, o qual é ocasionado pela quebra dos limites internos e externos da obra literária:

J'ai écrit hier le plan [du livre] et jeté les principales lignes. Pourtant, j'ai laissé les conclusions vagues et flottantes, voulant m'imposer une déduction non prévenue et découvrir peu à peu, au fil de l'évolution patiemment découlée, - d'autant plus ne voi-je pas très bien jusqu'où je pourrai pousser le drame, ni comment l'arrêter, ni pourquoi. (GIDE, 1986, p. 91-92 apud GOULET, 2006, p. 49).

Portanto, a problemática do l'auteur en abyme põe em evidência a experiência do autor "em gestação" por meio de um exercício de eterna interrogação e tem como objetivo esclarecer "I'énigme de soi-même pour soi" (GOULET, 2006, p. 56). Como podemos notar, na obra de André Gide a mise en abyme surge constantemente associada ao status de retroação, com personagens escritores, os quais possibilitam pela escritura a interlocução do autor consigo mesmo, conforme discutido nas páginas do Journal: "C'est une réciprocité que j'ai voulu indiquer; non plus dans les rapports avec les autres, mais avec soi-même" (GIDE, 1996, p. 170).

Também na obra clariciana, a mise en abyme surge da retroação revelada pela figura de um personagem escritor, bem como pela relação de duplicata ou espelhamento, cujos limites tendem a questionar a vulnerabilidade das definições teóricas impostas, obrigando o leitor a reconhecer o aspecto espelhado, poroso e incerto de seu texto. Tal procedimento percorre o diálogo interno e endogâmico, bem como externo e exogâmico, abrangendo outros textos da autora.

A mise en abyme corresponde, pois, a um meio capaz de transformar e transgredir a narrativa, apresentando-se como parte integrante de um objeto estético.

As observações acerca de si mesma parecem propiciar o entendimento contextual da escrita, além de fornecer um contato mais direto entre a escritora e seu público. Surgem aí colocações de ordem metalinguística, as quais permitem, por meio do jogo de fingimento e sinceridade, o exame da feitura de tais textos. Como se pode observar na 


\section{Revista do SELL}

v. 5 , no. 2

ISSN: $1983-3873$

crônica "A explicação que não explica" 6 , em que a autora compartilha com o leitor a gênese dos contos da coletânea Laços de família:

Não é fácil lembrar-me de como e por que escrevi um conto ou um romance. Depois que se despegam de mim, também eu os estranho. [...] De 'Devaneio e embriaguez de uma rapariga' sei que me diverti tanto que foi mesmo um prazer escrever. Enquanto durou o trabalho, estava sempre de um bom humor diferente do diário e, apesar de os outros não chegarem a notar, eu falava à moda portuguesa, fazendo, ao que me parece, experiência de linguagem. Foi ótimo escrever sobre a portuguesa. (LISPECTOR, 1999a, p. 238-239)

Embora temendo a exposição por parte da escrita, a autora desconstrói as próprias afirmações, jogando de forma lúdica com as certezas dos seus leitores. De acordo com Nádia Gotlib, "a linguagem por vezes mais solta dos textos de cunho jornalístico de Clarice Ihe traz sua imagem ao espelho" (1989, p. 140). Imagem distorcida e prismática à proporção que se revela no outro, no heterônimo a ser decifrado pelo leitor. Nesse sentido são significativas as palavras de Ângela em diálogo com o Autor em Um sopro de vida: "Eu sou uma atriz para mim. Eu finjo que sou uma determinada pessoa mas na realidade não sou nada" (LISPECTOR, 1999b, p. 40). Assim, a heteronímia obriga o leitor a perscrutar e caracterizar os traços da escrita das personas, denotando, de antemão, relações vertiginosas com a própria figura ortônima, Clarice Lispector ela-mesma.

No que tange ao póstumo Um sopro de vida, é possível observarmos um traçado metalinguístico inerente à escritura, especialmente no diálogo entre dois personagens, Ângela e Autor. Pautada por uma longa problematização da criação literária moderna, essa obra revela um horizonte de semelhanças com o romance $A$ hora da estrela, tanto no nível temático quanto formal. Tais semelhanças são partilhadas quanto à atitude de comentário e reflexão da obra acerca de seu acabamento e sua gênese como uma espécie de dobra especular sobre si mesma, na medida em que se alternam os dois monólogos: "[...] autor interposto e personagem feminina, dessa vez uma escritora (Ângela), ambos como heterônimos da romancista, Clarice Lispector, mais presente do que ausente" (NUNES, 1995, p. 169-170).

Desse modo, Um sopro de vida encarna a encenação dramatúrgica e performática de um embate agônico entre a criação e a criatura:

Tive um sonho nítido inexplicável: sonhei que brincava com o meu reflexo. Mas meu reflexo não estava num espelho, mas refletia uma outra pessoa que não eu. Por causa desse sonho é que inventei Ângela como meu

\footnotetext{
${ }^{6}$ Jornal do Brasil, 11 de outubro de 1969.
} 


\section{Revista do SELL}

v. 5 , no. 2

ISSN: $1983-3873$

reflexo? [...] Eu a esculpi com raízes retorcidas. É só por atrevimento que Ângela existe em mim. Quanto a mim reduzo tudo em palavras de rodaviva. Todos nós estamos sob pena de morte. Enquanto escrevo posso morrer. Um dia morrerei entre os fatos diversos. (LISPECTOR, 1999b, p. 27-28)

Como se vê, o jogo especular opera-se pelo desdobramento do narrador, na cisão entre Autor e Ângela, abarcando, ao longo da obra, a consciência da morte e do ser para a morte.

Ainda que seja uma criação de seu autor, a personagem Ângela apresenta-se com "personalidade própria", recapitulando, por meio das instâncias parafrásicas e paródicas, a própria obra de Clarice Lispector:

O objeto - a coisa - sempre me fascinou e de algum modo me destruiu. No meu livro $A$ cidade sitiada eu falo indiretamente no mistério da coisa. Coisa é bicho especializado e imobilizado. Há anos também descrevi um guarda-roupa. Depois veio a descrição de um imemorável relógio chamado Sveglia: relógio eletrônico que me assombrou e assombraria qualquer pessoa viva no mundo. (LISPECTOR, 1999b, p. 104-105)

Frases, passagens e títulos de obras de Clarice Lispector, "ortônima no meio de seus heterônimos" (NUNES, 1995, p. 170) surgem amalgamados tanto no discurso de Ângela quanto no do Autor e denotam a reflexão acerca do próprio código, formando "uma só escrita errante, empática, hiperbólica, repetitiva" (NUNES, 1995, p. 170), que tende a contaminar o leitor, mergulhado no mistério especular da linguagem clariciana.

\section{Considerações finais}

O presente artigo buscou realizar uma análise possível da obra especular de André Gide e Clarice Lispector. A fim de demonstrar o movimento narcísico das escritas gidiana e clariciana como objetos no qual se projetam forças expressivas e reflexivas, centradas no entrecruzamento do jogo de espelhos, foi necessário delimitar narrativas capazes de demonstrar essa condição.

Nesse sentido, o entendimento do fenômeno da mise en abyme perpassa, na escala de personagens da obra literária, o redobramento do próprio sujeito da narrativa, num movimento reflexivo: "O que primeiro cabe evidenciar, é que a obra de arte reflexiva é uma representação - e uma representação dotada dum grande poder de coesão interna" (DALLENBACH, 1979, p. 67-68). 


\title{
Revista do SELL
}

v. 5 , no. 2

ISSN: $1983-3873$

Assim, o corpus confirmou a identificação e o alcance da mise en abyme como forma transcendente, ou seja, como um mecanismo que ultrapassa a imagem do simples brasão presente nas considerações do autor francês. É o jogo não gratuito do olhar.

Nesse sentido, o espelho representa a dor de existir e a procura do ser por um lugar no mundo. Parece razoável inferir que os enredos aqui mencionados remontem a um traçado metalinguístico, apresentando o fazer artístico no confronto entre escrever e narrar.

Ao longo das discussões apontadas até aqui, o presente texto propõe alguns dados reflexivos, longe de conclusões finais. Caminhos que se bifurcam, que se encontram e que se completam: a poética de Gide e a de Lispector, ambas percorrendo a mesma trilha, alicerçadas pelo sentido do ser e da linguagem.

Como conclusão, deixamos ecoar a poesia de Ferreira Gullar, cujos versos consubstanciam e traduzem a eterna busca por si mesmo, revelada nas narrativas narcisistas de Gide e Lispector:

\author{
Carregar um espelho \\ é mais desconforto que vantagem: \\ a gente se fere nele \\ e ele \\ não nos devolve mais do que a paisagem \\ Não nos devolve o que ele não reteve: \\ o vento nas copas \\ o ladrar dos cães \\ a conversa na sala \\ barulhos sem os quais \\ não haveria tardes nem manhãs \\ (GULLAR, 2001, p. 321-322)
}

\section{Referências}

BARTHES, Roland. Literatura e metalinguagem. In: BARTHES, Roland. Crítica e verdade. Tradução Leyla Perrone-Moisés. São Paulo: Perspectiva, 2007. (Coleção Debates, 24). p. 27-30.

BORGES, Jorge Luís. Averroes' search. In: Borges, a personal anthology. Trans. Anthony Kerrigan. New York: Grove Press, 1967.

DALLENBACH, Lucien. Le livre et ses miroirs dans l'oeuvre romanesque de Michel Butor. Paris: Archives des Lettres Modernes, 1972. 


\section{Revista do SELL}

v. 5 , no. 2

ISSN: $1983-3873$

. Le recit spéculaire: essai sur la mise en abyme. Paris: Seuil, 1977.

Intertexto e autotexto. Intertextualidades - Revista de Teoria e Análises

Literárias. Tradução do original Poétique - Revue de Théorie et d'Analyse Littéraires por Clara Crabbé Rocha. Coimbra: Almedina, n. 27, 1979. p. 51-76.

FOUCAULT, Michel. Las meninas. In: FOUCAULT, Michel. As palavras e as coisas: uma arqueologia das ciências humanas. Tradução Salma Tannus Muchail. 8. ed. São Paulo: Martins Fontes, 1999. p. 3-22.

GIDE, André. Journal: tome I (1887-1925). Paris: Gallimard, 1996.

. Les cahiers et les poésies d'André Walter. Paris: Gallimard, 1948. (Col. Poésie). . Os moedeiros falsos. Tradução de Celina Portocarrero. Rio de Janeiro: Francisco Alves, 1983.

GOTLIB, Nádia Battella. Olhos nos olhos: Fernando Pessoa e Clarice Lispector. Remate de males. Campinas: UNICAMP, n. 9, maio. 1989. p. 139-145.

GOULET, Alain. L'auteur mis en abyme. Lettres Françaises. Araraquara: Departamento de Letras Modernas, UNESP-Fclar.n. 7, 2006, p. 39-58.

GULLAR, Ferreira. O espelho do guarda-roupa. In: GULLAR, Ferreira. Toda poesia (19501999). 11. ed. Rio de Janeiro: José Olympio, 2001. p. 321-322.

HUTCHEON, Linda. Thematizing narrative artifice: parody, allegory and the mise en abyme. In: HUTCHEON, Linda. Narcissistic narrative: the metafictional paradox. Ontario, Canada: Wilfrid Laurier University Press, 1980. p. 48-56.

LISPECTOR, Clarice. A hora da estrela. Rio de Janeiro: Francisco Alves, 1993.

A explicação que não explica. In: LISPECTOR, Clarice. A descoberta do mundo. Rio de Janeiro: Rocco, 1999a. p. 238-240.

. Um sopro de vida. Rio de Janeiro: Rocco, 1999b.

NOLASCO, Edgar César. Restos de ficção: a criação biográfico-literária de Clarice Lispector. São Paulo: Annablume, 2004.

NUNES, Benedito. O drama da linguagem: uma leitura de Clarice Lispector. 2. ed. São Paulo: Ática, 1995.

. Os destroços da introspecção. In: ZILBERMAN, Regina et al. Clarice Lispector: a narração do indizível. Porto Alegre: Artes e ofícios/EDIPUC, Instituto Cultural Judaico Marc Chagal, 1998. p. 35-48.

RICARDOU, Jean. Le récit abymé. In: RICARDOU, Jean. Le noveau roman. Paris: Seuil, 1978, p. 47-75. 


\section{Revista do SELL}

v. 5 , no. 2

ISSN: 1983-3873

VALÉRY, Paul. Monsieur Teste. In: VALÉRY, Paul. Oeuvres. T. 2. Paris: Gallimard, 1960. (Bibliothèque de la Pléiade, 148). 